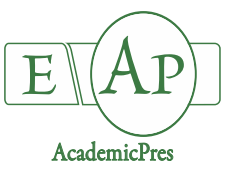

Jhou Y-J et al. (2021)

Notulae Botanicae Horti Agrobotanici Cluj-Napoca

Volume 49, Issue 1, Article number 12064

DOI: $10.15835 /$ nbha49112064

Research Article

\title{
Influence of fertilizer and salicylic acid treatments on growth, physiological, and antioxidant characteristics in green and red Perilla frutescens varieties
}

\author{
Yin-Jheng JHOU ${ }^{1 \mathrm{a}}$, Kuan-Hung LIN ${ }^{2 \mathrm{~b}}$, Chun-Wei WU ${ }^{1 *}$, \\ $\mathrm{Yu}-\mathrm{Sen} \mathrm{CHANG}^{1 *}$
}

\author{
${ }^{1}$ National Taiwan University, Department of Horticulture and Landscape Architecture, Taipei 106, Taiwan; \\ dodo322317@gmail.com; r88628115@ntu.edu.tw; yschang@ntu.edu.tw (*corresponding author) \\ ${ }^{2}$ Chinese Culture University, Department of Horticulture and Biotechnology, Taipei 111, Taiwan; rlin@faculty.pccu.edu.tw \\ ${ }^{a, b}$ These authors contributed equally to the work
}

\begin{abstract}
Perilla is herbaceous plant, functional food, and nutraceutical product with antioxidant properties. The objective of this study was to investigate the growth, reflectance indices, and antioxidant properties of $P$. frutescensspecies in response to fertilizer and salicylic acid (SA) applications. Two independent experiments were carried out in an environmentally controlled greenhouse: (1) pots of red-leaf and green-leaf cultivars divided into four groups treated with 10-30-20 (10N13.1P-16.6K), 15-10-30 (15N-4.4P-24.9K), 20-20-20 (20N-8.7P-16.6K), and 30-10-10 (30N-4.4P-8.3K) fertilizers for periods of 10 weeks, and (2) pots of red and green Perilla cultivars divided into five groups treated with 0 (control), 125, 250,500 , and 1,000 $\mu \mathrm{M}$ of SA for periods of 7 weeks. Wide variations occurred in the agronomic performance, soil-plant analysis development (SPAD) value, adjusted normalized difference vegetation index (NDVI), maximal quantum yield of PSII photochemistry (Fv/Fm), and antioxidant activity of the two Perilla varieties. All the measured traits were higher in green than in red Perilla under identical fertilizing, and all agronomic traits in green and red Perilla plants subjected to 125 and $500 \mu \mathrm{M}$ SA were better than in controls. The SPAD and NDVI values of all plants increased as N\% increased, the lowest $\mathrm{Fv} / \mathrm{Fm}$ values of all plants were observed under 15-10-30 fertilizer treatment, the lowest NDVI values were detected in controls, and the $\mathrm{Fv} / \mathrm{Fm}$ values of all plants decreased under 1,000 $\mu \mathrm{M} \mathrm{SA}$ treatment. These indices can be used as indicators to characterize the physiology of these plants and are suitable for evaluating their growth and development under specific fertilizer and SA treatments. Green Perilla leaf extract (PLE) contained higher rosmarinic acid (RA) concentration in each fertilizer treatment, and higher total phenolic (TP) and RA concentration in each SA treatment. However, red PLE contained higher caffeic acid (CA) concentration than green PLE in each fertilizer and SA treatment, implying that their two genotypes exhibited different abilities and specificities of photosynthetic metabolites, and that different varieties may prepare for 2,2-diphenyl-1-picrylhydrazyl (DPPH) radical scavenging activity by up-regulating TP, RA, and CA concentration differently. Thus, Perilla plants can be used as health foods due to high TP, RA, and CA concentration. To produce Perilla efficiently in industrial applications, we undertook to determine the optimum N-P-K fertilizer ratio and SA application for maximizing the growth and accumulation of TP, RA, and CA in Perillaplants.
\end{abstract}

Received: 02 Sep 2020. Received in revised form: 12 Dec 2020. Accepted: 15 Dec 2020. Published online: 04 Ian 2021.

From Volume 49, Issue 1, 2021, Notulae Botanicae Horti Agrobotanici Cluj-Napoca journal will use article numbers in place of the traditional method of continuous pagination through the volume. The journal will continue to appear quarterly, as before, with four annual numbers. 
Keywords: antioxidants; caffeic acid; fertilizer; salicylic acid; spectral reflectance; rosmarinic acid; total phenolic

\section{Introduction}

The global demand for medicinal plants is increasing. Perilla frutescensis an herbaceous plant belonging to the mint family Lamiaceae, and is widely cultivated in Eastern Asian countries. It contains high amounts of pigments and secondary metabolites in its leaves, and is considered an important medicinal plant (Ghimire et al., 2017). Perilla leaves contain natural antioxidants with health and nutritional benefits for reducing free radical-induced tissue injury and scavenging diverse reactive oxygen species (ROS) (Chao et al., 2014). A diet rich in Perilla plants offers protection against tumors, depression-related diseases, asthma, and infections, and enhances defense systems, maintains health, prevents oxidative stress-mediated diseases, and delays ageing processes (Beta et al., 2017; Caleja et al., 2017; Pintha et al., 2018). These protective effects are considered, in large part, to be related to various antioxidants, mainly phenolic compounds that are responsible for scavenging ROS by inhibiting the enzymes and chalet ions responsible for forming ROS in cells (Kagawa et al., 2019; Ghimire et al., 2019). In addition, because of their taste, flavor, and health functions, the consumption of herbaceous plants (e.g. Perilla) has increased in Asia, Europe, USA, and Canada in recent years (Chen et al., 2019). Investigations of the phytochemicals in Perilla plants and their associated functions are essential for exploring the potential for and deeper understanding of this plant.

Physiological parameters such as photosynthetic performance and chlorophyll (Chl) content greatly influence plant survival (Devitt et al., 2005). Visual observations frequently result in experimental errors, whereas destructive measurements damage plants and make further experiments nearly impossible. Chlorophyll fluorescence (ChlF) measurement, such as the maximal quantum yield of photosystem II (PSII) photochemistry $(\mathrm{Fv} / \mathrm{Fm})$, is a noninvasive technique that has been widely used in a range of photosynthetic organisms and tissues to study functional changes in the photosynthetic apparatus under abiotic stress conditions (Huang et al., 2013). However, no effort has been made to study the photosynthetic indices and secondary metabolites in response to fertilizer and salicylic acid (SA) treatments in P. frutescens. Reflectance spectroscopy, another underexploited, noninvasive technique that can be used in physiological studies, is simple, rapid, and nondestructive (Levizouet al., 2005). Various reflectance spectra from leaves have been employed to calculate vegetation indices used for monitoring plant growth. Reflectance spectra are altered when stress occurs, and these alterations can be used to calculate different vegetation indices. For example, the adjusted normalized difference vegetation index (NDVI) has been linked to photosynthetic light-use efficiency (Ballester et al., 2018). Previously, we found that leaf Soil Plant Analysis Development (SPAD), NDVI, and $\mathrm{Fv} / \mathrm{Fm}$ indices are accurate proxies of leaf nitrogen concentration and can be used as non-destructive estimations of the proper timing for $\mathrm{N}$-solution irrigation of Pentas lanceolata (Wu et al., 2015). Hence, these spectral reflectance indices might be useful for measuring leaf pigments and secondary metabolites when developing indices for nondestructive estimations, and we attempted to determine whether these indices could be used on Perilla plants as sensitive metrics for estimating leaf ChlF corresponding to antioxidant activities under various fertilizer and $S A$ treatments.

Generally, plants grow rapidly and produce better biomass yields in less stressful environments. Many studies have revealed that the constitution and concentration of phenolic compounds and metabolites in medicinal plants, including Perilla, are largely influenced by various factors such as growth season, environment, light intensity or quality, cultivation methodology, phenological stage, nutrient level, and harvest time (Saeb and Gholamrezaee, 2012; Yoshimatsu, 2012; Chauhan et al., 2013; Selmar and Kleinwachter, 2013; Ha et al., 2012; Kiazolu et al., 2016; Lu et al., 2017; Kim et al., 2017; Umakanta and Oba, 2018). Moreover, Hikosaka et al. (2017) reported that greenhouse cultivation is an effective method for the steady production of medicinal plants because environmental conditions can be controlled, and furthermore, safer medicinal plants are produced with the use of agrochemicals. Ogawa et al. (2018) also demonstrated that bioactive compound 
concentrations in red Perilla increased with nutrient solution temperatures in a greenhouse. The accumulation of these phenolic compounds and metabolites may be increased independently, and rather unpredictably, in response to individual or combinations of environmental stresses. Thus, a sustainable medicinal plant production system that can manage environmental factors is needed to obtain a stable supply of Perilla plants with uniform quality. There is limited information available regarding the adaptability and management of fertilizer and salicylic acid (SA) treatments on the growth and antioxidant characteristics in green and red Perilla frutescens varieties. Red-leaf $P$. frutescens is an indigenous Taiwanese vegetable widely used for its rich aroma, and green-leaf $P$. frutescens is a popular variety grown in Taiwan for consumption as a fresh vegetable. Metabolites are important factors for the quality and antioxidant properties of Perilla leaves. Therefore, the objective of this study was to investigate the 2,2-diphenyl-1-picrylhydrazyl (DPPH) radical scavenging activity and concentration of total phenolics (TP), rosmarinic acid (RA), and caffeic acid (CA) in $P$. frutescens cultivars in response to fertilizers with various nitrogen $(\mathrm{N})$, phosphorus $(\mathrm{P})$, and potassium $(\mathrm{K})$ levels and different $\mathrm{SA}$ treatments. The efficient and responsible use of fertilizer and SA in sustainable agriculture is important for maintaining high biomass production and quality. Moreover, spectral reflectance parameters can be used to detect fertilizer and SA treatments in crop species having contrasting phonologies for developing management practices that enhance field cultivation. The results also have the potential to be used in controlled environments to maximize the efficient growth, development, and metabolic capability of Perilla plants grown for economic benefit.

\section{Materials and Methods}

Plant materials, cultural practice, experimental design, and treatments

Seeds of red-leaf $P$. frutescens (var. 'crispa forma purpurea') and green-leaf $P$. frutescens (var. 'crispa forma viridis') were purchased from Known-You Seed Co. (Taipei, Taiwan), germinated, and grown in 128cell flats $(60 \mathrm{~cm} \times 31 \mathrm{~cm}, 3 \times 3 \times 3.5 \mathrm{~cm}$ each cell $)$ for one week. The soil used was a commercial potting mix of peat moss, perlite, and vermiculite (4:1:1 v/v/v, Known-You Co., Taipei, Taiwan). When plants were grown to the fourth-leaf stage, they were transplanted into $15 \mathrm{~cm}$ diameter plastic pots $(1 \mathrm{~L}$, one plant per pot) containing the above-mentioned medium and placed in environmentally controlled greenhouses at National Taiwan University (NTU, latitude $25.01^{\circ} \mathrm{N}$ ). The growth environment was controlled to a $14 / 10 \mathrm{~h}$ day/night photoperiod at $25 / 20^{\circ} \mathrm{C}$ with a relative humidity of $80 \%$ and $300 \mu \mathrm{mol} \cdot \mathrm{m}^{-2} / \mathrm{s}^{-1}$ photosynthetic photon flux. Plants were watered twice a week, and a 20N-8.7P-16.6K water-soluble chemical fertilizer (Peters 20-20-20, Marysville, Ohio, USA) was applied at a rate of $1 \mathrm{~g} \mathrm{~L}^{-1}$ to each pot weekly. Plants were grown for 14 days, and those at a relatively uniform size were selected and randomly separated into different groups for the various $\mathrm{N}$ $\mathrm{P}-\mathrm{K}$ ratio and $\mathrm{SA}$ concentration experiments.

Pots of red-leaf and green-leaf cultivars were divided into four group treated with Peter's fertilizer 1030-20 (10N-13.1P-16.6K), 15-10-30 (15N-4.4P-24.9K), 20-20-20 (20N-8.7P-16.6K), or 30-10-10 (30N$4.4 \mathrm{P}-8.3 \mathrm{~K}$ ) for a 10 -week period (April $14 \sim$ June 29,2017 ) in the above-mentioned greenhouse at a $14 \mathrm{~h}$ photoperiod, $25 / 20^{\circ} \mathrm{C}$ temperature regime, and $600 \mu \mathrm{mol} \mathrm{m}{ }^{-2} \mathrm{~s}^{-1}$ radiation. Each pot was manually irrigated with $200 \mathrm{~mL}$ of fertilizer at $1 \mathrm{~g} \cdot \mathrm{L}^{-1}$ until gravity water was released, and each pot was fertilized twice weekly in the late afternoon. Nine replicates of each fertilizer treatment of each cultivar in the four treatments ( 36 pots in total each variety) were randomly placed in the greenhouse.

Pots of red-leaf and green-leaf cultivars were divided into five groups treated with 0 (control), 125, 250, 500 , and 1,000 $\mu \mathrm{M}$ SA for a period of seven weeks (July $1 \sim$ August 23, 2017) in the above-mentioned environmentally controlled greenhouse at NTU. All plants manually received $200 \mathrm{~mL}$ of SA to the soil mix twice weekly in the late afternoon throughout the experiment. Nine replicates from each concentration in each cultivar for the five treatments ( 45 pots in total each variety) were randomly placed in the greenhouse. 


\section{Data collection and growth analyses}

Three leaves from each plant were clipped, immediately frozen in liquid nitrogen, and then stored at $70{ }^{\circ} \mathrm{C}$ for subsequent analyses. We measured agronomic performance and values of SPAD, NDVI, Fv/Fm, and DPPH from those three leaf samples of each plant, and 27 fresh leaves from 9 pots were used. All analyses were performed at the end of each experimental period. Plant height was measured as the height $(\mathrm{cm})$ above the soil with a digital caliper (Digipa, Mitutoyo Co., Tokyo, Japan). The total number of leaves over $10 \mathrm{~mm}$ in length were counted after detachment from the basal ends of the stems. The fresh weights (FW) of shoots and leaves from nine replicates were measured as green shoots and leaves, and clipped at the soil surface to assess biomass accumulation. The dry weights (DW) of shoots and leaves from nine replicates were obtained after drying in an oven at $70^{\circ} \mathrm{C}$ for six days.

\section{Determination of spectral reflectance and ChIF}

Healthy, fully expanded mature leaves from the middle to upper portions of each plant were used to determine total chlorophyll content using a soil-plant analysis development (SPAD) analyzer (SPAD-502 Chlorophyll Meter, Konica Minolta, Tokyo, Japan). Spectral reflectance was measured from the third leaves at wavelengths of 200 900 nm using an integrating sphere fitted to a scanning spectrophotometer (PolyPen RP 400, Photon Systems Instruments, Prague, Czech Republic). The adjusted normalized difference vegetation index (NDVI) was calculated as (R750 - R705) / (R750 + R705 - 2× R445) (Weng et al., 2010).

Potted plants were moved into the shade before sunrise at 05:30 06:00. After dark-adapted for $30 \mathrm{~min}$, the leaves were measured for ChlF parameters with a portable fluorometer (MINI-PAM, Walz, Effeltrich, Germany) at ambient temperature (Weng et al., 2010). The middle portions of all tested leaves of each plant in both varieties were measured. Minimal ChlF (Fo) and maximal ChlF (Fm) values of the dark-adapted samples were respectively determined using the modulated irradiation of a weak LED beam (measuring light) and a saturating pulse. We then calculated the maximum photochemical quantum yield ( $\mathrm{Fv} / \mathrm{Fm}$ ), where $\mathrm{Fv}$, the yield of variable fluorescence, was calculated as (Fm - Fo). When measuring Fv/Fm, samples were first acclimated to shade conditions to ensure that all reaction centers were in an open state and there was minimal non-photochemical dissipation of excitation energy. Measurements were recorded using WinControl-3 software (Heinz Walz, Effeltrich, Germany).

\section{Measurement of DPPH radical scavenging activity and TP concentration}

After being harvested, twenty-seven freshly picked leaf samples were carefully washed with tap water, lyophilized using a freeze dryer (FD-5060, Panchum Scientific, Taipei, Taiwan), and stored at $-20{ }^{\circ} \mathrm{C}$. Antioxidant capacity of DPPH free radical-scavenging activity was determined according to the method of Yoshikiet al. (2001). Briefly, to extract target compounds, $0.15 \mathrm{~g}$ of dry leaf powder was immersed in $10 \mathrm{ml}$ $80 \%$ methanol at room temperature. The liquid phase was then separated from the debris by filtration under a vacuum using filter paper to obtain the crude $P$. frutescens leaf extract (PLE), which was used for further experiments. Serial dilution $0.2 \mathrm{ml}$ aliquots of the methanol PLE were added to $0.05 \mathrm{ml}$ of a DPPH solution $(1 \mathrm{mM}$ in methanol). The mixture was then well mixed and left at room temperature for $60 \mathrm{~min}$ in the dark before measuring absorbance at $517 \mathrm{~nm}$ using a Hitachi U-2000 type spectrophotometer. Radical-scavenging activity was calculated using the following equation: Scavenging effect $(\%)=[1$ - (absorbance of sample at 517 $\mathrm{nm} /$ absorbance of control at $517 \mathrm{~nm})] \times 100 \%$. Methanol was used instead of a sample as the control.

The TP concentration of PLE was determined according to the method of Taga et al. (1984). Standard gallic acid and an aliquot of the acidic methanolic extract were diluted with acidified methanol solution containing $0.5 \% \mathrm{HCl}$. Two $\mathrm{ml}$ of $2 \% \mathrm{Na}_{2} \mathrm{CO}_{3}$ were mixed into each sample of $100 \mu \mathrm{l}$ and allowed to equilibrate for $2 \mathrm{~min}$ before adding 50\%Folin-Ciocalteu reagent (Sigma Aldrich, St. Louis, MO, USA). Absorbance at 760 $\mathrm{nm}$ was measured at room temperature using the Varioskan Flash Multimode Reader (Thermo Scientific, Rockford, IL, USA). The standard curve for gallic acid was used to calculate total phenolic levels. TP 
concentration was expressed as the mg gallic acid equivalent (GAE) $\mathrm{g}^{-1}$ of DW. The standard curve equation was $y=0.4995 x-0.011$, where $R^{2}=0.9944$. The assay was run in triplicate for each sample.

\section{Determination of $R A$ and $C A$ concentrations}

To separate and identify antioxidant phenolic compounds in the PLE, reverse phase C18 highperformance liquid chromatography (HPLC) was used as described by Liu et al. (2013). The Hypersil ODS C18 column $(250 \times 4.6 \mathrm{~mm}, 5 \mu \mathrm{m})$ was connected to the LC-200 HPLC system (Perkin-Elmer, Waltham, MA, USA) and equilibrated with $0.05 \%$ aqueous trifluoroacetic acid. Ten microliters of methanolic PLE was used for HPLC analysis after filtration through a $0.22 \mu \mathrm{m}$ syringe filter (Millex-GV, Millipore, Sigma Aldrich), injected, and eluted with $0.1 \%$ aqueous formic acid and acetonitrile. The flow rate was $1 \mathrm{~mL} / \mathrm{min}$ at $25^{\circ} \mathrm{C}$. Collected fractions of the eluent were all in $1 \mathrm{~mL}$ aliquots, and absorbance at $330 \mathrm{~nm}$ of the eluent was scanned by a LC-785A UV/VIS Detector. Peak identification was performed by comparing the retention time and ultraviolet absorption spectrum of the eluting peaks with those of polyphenol standards. Authentic standards for CA and RA were used to identify the phenolic compounds of $P$. frutescens. A series of standard solutions in concentrations ranging from 5 to $25 \mu \mathrm{g} \cdot \mathrm{mL}^{-1}$ were tested to determine the calibration curve. The regression equations for RA and CA were calculated in the form of $y=a x+b$, where $y$ and $x$ were peak area and amount of standard injected, respectively, and all calibration curves had coefficients of linear correlation $\mathrm{r}^{2}>0.998$.

\section{Statistical analysis}

The measurements of phenotypic traits, spectral reflectance, and antioxidant ability were analyzed by a completely randomized analysis of variance (ANOVA) that compared the different fertilizers (N-P-K ratio) and SA concentrations for each parameter. For significant values, means were separated by Fisher's least significant difference (LSD) test at $p<0.05$ using SAS ver. 9 (SAS Institute, Cary, NC, USA).

\section{Results}

Fertilizer effects on growth traits, spectral reflectance, and antioxidant activity in green and red $P$. frutescens

Table 1 illustrates that plant height, leaf and branch numbers, and both DW and FW of shoots and leaves differed in the two genotypes of $P$. frutescens after 10 weeks of cultivation at four different chemical fertilizer N-P-K ratios. Plant height from the 30-10-10 treatment $(78.5 \mathrm{~cm})$ was significantly taller than the other fertilizer treatments $(72.9 \sim 74.7 \mathrm{~cm})$ in green Perilla plants. However, red Perilla plants treated with 1510-30 fertilizer had a significant shorter average height $(39.5 \mathrm{~cm})$ than those with other fertilizer treatments $(43.0 \sim 43.5 \mathrm{~cm})$, indicating that different fertilizer ratios affected plant heights differently (Figure S1).In the green variety, a significantly higher leaf number occurred in the 30-10-10 treatment (191.3 per plant) compared to other fertilizer treatments (162.7 170.8 per plants), but green variety maximum (76.0) and minimum (67.3) leaf numbers were achieved with the application of 30-10-10 and 15-10-30 treatments, respectively. The application of fertilizer at any N-P-K level did not affect the branch number of green Perilla plants, but the 1510-30 treatment significantly decreased the branch number (10.2 per plant) of red Perilla plants compared to other fertilizer treatments $(13.7 \sim 15.0$ per plant).Shoot FW (159.4 g/plant) and leaf FW ( $97.3 \mathrm{~g} /$ plant $)$ of green Perilla with the 30-10-10 fertilizer treatment were significantly higher than other treatments, except for leaf FW (96.7 g/plant) with 15-10-30 treatment, whereas shoot and leaf FW of red Perilla showed no significant differences among all fertilizer treatments. A significantly lower shoot DW $(20.12 \mathrm{~g} / \mathrm{plant})$ and leaf DW (11.06 g/plant) in green Perilla plants was detected in the 10-30-20 treatment compared to other treatments (shoot DW of $23.60 \sim 25.39 \mathrm{~g} /$ plant and leaf DW of $13.31 \sim 14.51 \mathrm{~g} /$ plant). Maximal and significant increases in shoot DW and leaf DW were found with the 30-10-10 treatment at 9.86 and 5.04 $\mathrm{g} /$ plant, respectively, compared to $10-30-20$ and 15-10-30 treatments. It is worth noting that in all chemical 
fertilizer treatments, the FW and DW of shoots and leaves were increased with increases in the fertilizer nitrogen ratio from $10 \%$ to $30 \%$.

\begin{tabular}{|c|c|c|c|c|c|c|c|c|}
\hline Variety & $\begin{array}{c}\text { Fertilizer } \\
\text { treatment } \\
\left(\mathrm{N}-\mathrm{P}_{2} \mathrm{O}_{5-}\right. \\
\left.\mathrm{K}_{2} \mathrm{O} \text { ratio }\right)\end{array}$ & $\begin{array}{l}\text { Plant } \\
\text { height } \\
(\mathrm{cm})\end{array}$ & $\begin{array}{c}\text { Leaf } \\
\text { number } \\
\text { (per plant) }\end{array}$ & $\begin{array}{c}\text { Branch } \\
\text { number } \\
\text { (per plant) }\end{array}$ & $\begin{array}{c}\text { Shoot } \\
\text { fresh } \\
\text { weight } \\
\text { (g/plant) }\end{array}$ & $\begin{array}{l}\text { Leaf fresh } \\
\text { weight } \\
\text { (g/plant) }\end{array}$ & $\begin{array}{l}\text { Shoot dry } \\
\text { weight } \\
\text { (g/plant) }\end{array}$ & $\begin{array}{c}\text { Leaf dry } \\
\text { weight } \\
\text { (g/plant) }\end{array}$ \\
\hline \multirow{4}{*}{$\begin{array}{l}\text { Green } \\
\text { Perilla }\end{array}$} & $10-30-20$ & $74.1 \mathrm{~b}$ & $170.8 \mathrm{~b}$ & $14.8 \mathrm{a}$ & $115.8 \mathrm{c}$ & $70.0 \mathrm{c}$ & $20.12 b$ & $11.06 \mathrm{~b}$ \\
\hline & $15-10-30$ & $72.9 \mathrm{~b}$ & $162.7 \mathrm{~b}$ & $15.2 \mathrm{a}$ & $142.5 \mathrm{~b}$ & $96.7 \mathrm{a}$ & $23.60 \mathrm{a}$ & $13.31 \mathrm{a}$ \\
\hline & $20-20-20$ & $74.7 \mathrm{~b}$ & $170.2 \mathrm{~b}$ & $16.4 \mathrm{a}$ & $145.6 \mathrm{~b}$ & $86.3 \mathrm{~b}$ & $24.09 \mathrm{a}$ & $13.47 \mathrm{a}$ \\
\hline & $30-10-10$ & $78.5 \mathrm{a}$ & $191.3 \mathrm{a}$ & $15.1 \mathrm{a}$ & $159.4 \mathrm{a}$ & $97.3 \mathrm{a}$ & $25.39 \mathrm{a}$ & $14.51 \mathrm{a}$ \\
\hline \multirow{4}{*}{$\begin{array}{c}\text { Red } \\
\text { Perilla }\end{array}$} & $10-30-20$ & $43.5 \mathrm{a}$ & $71.7 \mathrm{~b}$ & $15.0 \mathrm{a}$ & $68.0 \mathrm{a}$ & $32.5 \mathrm{a}$ & $8.42 \mathrm{~b}$ & $4.36 \mathrm{~b}$ \\
\hline & $15-10-30$ & $39.5 \mathrm{~b}$ & $67.3 c$ & $10.2 \mathrm{~b}$ & $69.8 \mathrm{a}$ & $33.5 \mathrm{a}$ & $8.96 \mathrm{~b}$ & $4.38 \mathrm{~b}$ \\
\hline & $20-20-20$ & $43.0 \mathrm{a}$ & $75.0 \mathrm{a}$ & $13.7 \mathrm{a}$ & $70.4 \mathrm{a}$ & $34.5 \mathrm{a}$ & $9.84 \mathrm{a}$ & $4.84 \mathrm{ab}$ \\
\hline & $30-10-10$ & $43.1 \mathrm{a}$ & $76.0 \mathrm{a}$ & $14.5 \mathrm{a}$ & $72.2 \mathrm{a}$ & $35.9 \mathrm{a}$ & $9.86 \mathrm{a}$ & $5.04 \mathrm{a}$ \\
\hline
\end{tabular}

Table 1. Effects of fertilizers on plant height, leaf number, branch number, shoot fresh weight, leaf fresh weight, shoot dry weight, and leaf dry weight of green and red Perilla frutescens plants over a 10-week period

Means in the same column within treatments of each cultivar followed by different letters are significantly different at $p \leq 0.05$ by least significant difference (LSD). Each treatment is assumed to be dependent on the other

Table 2 shows the differential responses in both varieties' ChlF and spectral reflectance values for different fertilizer treatments. The SPAD values of green Perilla with 10-30-20 and 15-10-30 fertilizer treatments showed no significant difference (30.1and 32.9, respectively), but significant increases in SPAD values were observed with both 20-20-20 and 30-10-10 treatments (34.9 and 37.0, respectively). The highest (42.0) and lowest (33.3) SPAD values of red Perilla were detected in 30-10-10 and 10-30-20 treatments, respectively. NDVI in green plants showed significantly lower values with 10-30-20 treatment (0.666) compared to other fertilizer treatments $(0.684 \sim 0.714)$. The trend and rate of the NDVI values in red Perilla under various fertilizers were similar to green Perilla. Green plants under 10-30-20 and 30-10-10 treatments exhibited significantly higher $\mathrm{Fv} / \mathrm{Fm}$ values $(0.831 \sim 0.834)$ compared to other temperature treatments $(0.821$ $\sim 0.826)$. A significantly lower $\mathrm{Fv} / \mathrm{Fm}$ value (0.764) with $15-10-30$ treatment was observed in red plants compared to other treatments $(0.820 \sim 0.825)$.

Table 3 presents DPPH radical scavenging activity and TP, RA, and CA concentration in extracts of different $P$. frutescens species under various fertilizer treatments. The trends and rates of TP, RA, and CA concentration under different fertilizer treatments varied between genotypes. For example, in green Perilla, the TP concentration in 10-30-20 and 15-10-30 treatments (respectively 142.5 and $127.3 \mathrm{mg} \mathrm{GAE} / \mathrm{g} \mathrm{DW}$ ) were significantly higher than in the 20-20-20 and 30-10-10 treatments (respectively 87.7 and $99.1 \mathrm{mg} \mathrm{GAE} / \mathrm{g}$ DW), whereas in red Perilla, the TP concentration (98.0 mg GAE/g DW) in the 10-30-20 treatment was significantly lower than in other treatments $(111.3 \sim 114.4 \mathrm{mg}$ GAE/g DW). Significantly lower RA concentration in green and red Perilla plants (867.1 and $408.2 \mathrm{mg} / \mathrm{kg}$ DW, respectively) occurred in response to 30-10-10 treatment compared to other fertilizer treatments. Nevertheless, in green Perilla plants, significantly lower CA concentration $(16.9 \mathrm{mg} / \mathrm{kg} \mathrm{DW})$ was observed in the 10-30-20 treatment compared to other treatments, but no significant differences appeared among treatments in the CA concentration of red Perilla plants. Notably, when genotypes were compared across fertilizer treatments, red Perilla plants exhibited higher CA concentration than green Perilla plants with all treatments. DPPH radical scavenging activity in all plants was not significantly affected by the different chemical fertilizer treatments. 
Table 2. Effects of fertilizers on SPAD, NDVI, and Fv/Fm values of leaves in green and red Perilla frutescens plants over a 10-week period

\begin{tabular}{|c|c|c|c|c|}
\hline \multirow{3}{*}{ Variety } & $\begin{array}{c}\text { Fertilizer } \\
\text { treatment }\left(\mathrm{N}-\mathrm{P}_{2} \mathrm{O}_{5-}\right. \\
\mathrm{K}_{2} \mathrm{O} \text { ratio }\end{array}$ & $\begin{array}{c}\text { SPAD } \\
\text { value }\end{array}$ & $\begin{array}{c}\text { NDVI } \\
\text { value }\end{array}$ & $\begin{array}{c}\text { Fv/Fm } \\
\text { value }\end{array}$ \\
\hline \multirow{4}{*}{ Green Perilla } & $10-30-20$ & $30.1 \mathrm{c}$ & $0.666 \mathrm{c}$ & $0.831 \mathrm{a}$ \\
\cline { 2 - 5 } & $15-10-30$ & $32.9 \mathrm{c}$ & $0.684 \mathrm{~b}$ & $0.821 \mathrm{~b}$ \\
\cline { 2 - 5 } & $20-20-20$ & $34.9 \mathrm{~b}$ & $0.703 \mathrm{a}$ & $0.826 \mathrm{~b}$ \\
\hline \multirow{3}{*}{ Red Perilla } & $30-10-10$ & $37.0 \mathrm{a}$ & $0.714 \mathrm{a}$ & $0.834 \mathrm{a}$ \\
\cline { 2 - 5 } & $10-30-20$ & $33.3 \mathrm{c}$ & $0.629 \mathrm{c}$ & $0.820 \mathrm{a}$ \\
\cline { 2 - 5 } & $15-10-30$ & $38.1 \mathrm{~b}$ & $0.649 \mathrm{~b}$ & $0.764 \mathrm{~b}$ \\
\cline { 2 - 5 } & $20-20-20$ & $40.0 \mathrm{ab}$ & $0.660 \mathrm{a}$ & $0.825 \mathrm{a}$ \\
\hline
\end{tabular}

Means in the same column within treatments of each cultivar followed by different letters are significantly different at $p \leq 0.05$ by least significant difference (LSD). Each treatment is assumed to be dependent on the other

Table 3. Effects of fertilizers on DPPH radical scavenging activity, total phenolic, rosmarinic acid, and caffeic acid concentration of leaves in green and red Perilla frutescens plants over a 10-week period

\begin{tabular}{|c|c|c|c|c|c|}
\hline \multirow{3}{*}{ Variety } & $\begin{array}{c}\text { Fertilizer } \\
\text { treatment }(\mathrm{N}- \\
\left.\mathrm{P}_{2} \mathrm{O}_{5}-\mathrm{K}_{2} \mathrm{O} \text { ratio }\right)\end{array}$ & $\begin{array}{c}\text { DPPH radical } \\
\text { scavenging } \\
\text { activity }(\%)\end{array}$ & $\begin{array}{c}\text { Total phenolic } \\
(\mathrm{mg} \mathrm{GAE} / \mathrm{g} \\
\mathrm{DW})\end{array}$ & $\begin{array}{c}\text { Rosmarinic } \\
\text { acid } \\
(\mathrm{mg} / \mathrm{kg} \mathrm{DW})\end{array}$ & $\begin{array}{c}\text { Caffeic } \\
\text { acid } \\
(\mathrm{mg} / \mathrm{kg} \mathrm{DW})\end{array}$ \\
\hline \multirow{4}{*}{ Green Perilla } & $10-30-20$ & $84.6 \mathrm{a}$ & $142.5 \mathrm{a}$ & $1461.7 \mathrm{a}$ & $16.9 \mathrm{~b}$ \\
\cline { 2 - 6 } & $15-10-30$ & $84.1 \mathrm{a}$ & $127.3 \mathrm{a}$ & $1353.1 \mathrm{a}$ & $24.6 \mathrm{a}$ \\
\cline { 2 - 6 } & $20-20-20$ & $81.1 \mathrm{a}$ & $87.7 \mathrm{~b}$ & $1352.3 \mathrm{a}$ & $21.1 \mathrm{a}$ \\
\cline { 2 - 6 } & $30-10-10$ & $82.6 \mathrm{a}$ & $99.1 \mathrm{~b}$ & $867.1 \mathrm{~b}$ & $20.2 \mathrm{a}$ \\
\hline \multirow{3}{*}{ Red Perilla } & $10-30-20$ & $91.8 \mathrm{a}$ & $114.4 \mathrm{a}$ & $1036.1 \mathrm{a}$ & $39.7 \mathrm{a}$ \\
\cline { 2 - 6 } & $15-10-30$ & $90.6 \mathrm{a}$ & $113.0 \mathrm{a}$ & $737.1 \mathrm{~b}$ & $42.5 \mathrm{a}$ \\
\cline { 2 - 6 } & $20-20-20$ & $91.5 \mathrm{a}$ & $111.3 \mathrm{a}$ & $519.3 \mathrm{c}$ & $42.4 \mathrm{a}$ \\
\cline { 2 - 6 } & $30-10-10$ & $88.9 \mathrm{a}$ & $98.0 \mathrm{~b}$ & $408.2 \mathrm{~d}$ & $45.0 \mathrm{a}$ \\
\hline
\end{tabular}

Means in the same column within treatments of each cultivar followed by different letters are significantly different at $p \leq 0.05$ by least significant difference (LSD). Each treatment is assumed to be dependent on the other

Effects of $S A$ concentration on growth, spectral reflectance, and antioxidant ability in green and red $P$. frutescens

Table 4 lists the measured changes in plant height, leaf and branch numbers, and the DW and FW of shoots and leaves for the various SA concentration treatments over the seven-week period. Under different $S A$ treatments, both red and green genotypes exhibited the same pattern in plant height, which tended to decrease with increasing SA concentration. Green plant heights under 125 and $250 \mu \mathrm{M} \mathrm{SA}$ treatments (respectively 49.8 and $47.5 \mathrm{~cm}$ ) were significantly taller than those given $1000 \mu \mathrm{M} \mathrm{SA}$ and controls (respectively 40.3 and 40.0 $\mathrm{cm})$. Red Perilla plants subjected to 125 and $500 \mu \mathrm{M}$ SA ( 25.1 and $24.5 \mathrm{~cm}$, respectively) were significantly taller than those given $1000 \mu \mathrm{M}$ of SA and he controls $(21.6$ and $23.2 \mathrm{~cm}$, respectively) (Figure S2). Significantly higher leaf numbers for green and red Perilla plants were observed in 125 and $500 \mu \mathrm{M}$ SA treatments, with 63.7 and 67.0 per plant, respectively, compared to $1000 \mu \mathrm{M} \mathrm{SA}$ and controls. Branch numbers of all Perilla plants were not sensitive to SA treatment, and branch numbers did not show a significant difference in response to SA. Significantly lower shoot FW (29.9 g/plant) and leaf FW (18.1 g/plant) in the green variety were detected in controls compared to SA treatments, whereas significant higher shoot FW (28.9 $\mathrm{g} /$ plant $)$ and leaf FW (16.2 g/plant $)$ in the red variety were detected in the $500 \mu \mathrm{M} \mathrm{SA}$ treatment compared to controls. Moreover, in green plants, significantly increased shoot DW (4.31 g/plant) and leaf DW (2.66 $\mathrm{g} / \mathrm{plant}$ ) were detected at 125 and $500 \mu \mathrm{M} \mathrm{SA}$ treatment, respectively, compared to other treatments. In red plants, significantly higher shoot DW was detected in the $500 \mu \mathrm{M} \mathrm{SA}$ treatment $(3.89 \mathrm{~g} / \mathrm{plant})$ compared to 
controls $(2.96 \mathrm{~g} / \mathrm{plant})$, while leaf DW remained low $(1.89 \mathrm{~g} / \mathrm{plant})$ in controls compared to other treatments (2.04 $2.14 \mathrm{~g} /$ plant $)$.

As shown in Table 5, there were no significant differences among SA treatments in the SPAD values of all plants, but different $P$. frutescens varieties possessed different NDVI and $\mathrm{Fv} / \mathrm{Fm}$ values in response to various SA concentrations. NDVI values for both cultivars tended to decrease with increases in SA concentration, and the lowest NDVI in green and red varieties were 0.642 and 0.634 , respectively. The lowest $\mathrm{Fv} / \mathrm{Fm}$ values for green and red plants, at 0.809 and 0.798 , respectively, were detected in the $1,000 \mu \mathrm{M} \mathrm{SA}$ treatment.

Table 4. Effects of salicylic acid (SA) concentration on plant height, leaf number, branch number, shoot fresh weight, leaf fresh weight, shoot dry weight, and leaf dry weight of green and red Perilla frutescens plants over a 7 -week period

\begin{tabular}{|c|c|c|c|c|c|c|c|c|}
\hline Variety & $\begin{array}{c}\mathrm{SA} \\
\text { treatment } \\
(\mu \mathrm{M})\end{array}$ & $\begin{array}{l}\text { Plant } \\
\text { height } \\
(\mathrm{cm})\end{array}$ & $\begin{array}{c}\text { Leaf } \\
\text { number } \\
\text { (per plant) }\end{array}$ & $\begin{array}{c}\text { Branch } \\
\text { number } \\
\text { (per plant) }\end{array}$ & $\begin{array}{c}\text { Shoot } \\
\text { fresh } \\
\text { weight } \\
\text { (g/plant) }\end{array}$ & $\begin{array}{c}\text { Leaf fresh } \\
\text { weight } \\
\text { (g/plant) }\end{array}$ & $\begin{array}{c}\text { Shoot } \\
\text { dry weight } \\
\text { (g/plant) }\end{array}$ & $\begin{array}{c}\text { Leaf } \\
\text { dry weight } \\
\text { (g/plant) }\end{array}$ \\
\hline \multirow{4}{*}{$\begin{array}{l}\text { Green } \\
\text { Perilla }\end{array}$} & 0 & $40.0 \mathrm{~b}$ & $56.3 c$ & $8.1 \mathrm{a}$ & $29.9 \mathrm{~b}$ & $18.1 \mathrm{~b}$ & $3.25 \mathrm{~d}$ & $2.15 \mathrm{c}$ \\
\hline & 125 & $49.8 \mathrm{a}$ & $63.7 \mathrm{a}$ & $8.5 \mathrm{a}$ & $37.4 \mathrm{a}$ & $23.0 \mathrm{a}$ & $4.31 \mathrm{a}$ & $2.39 \mathrm{~b}$ \\
\hline & 250 & $47.5 \mathrm{a}$ & $61.3 \mathrm{ab}$ & $8.7 \mathrm{a}$ & $34.2 \mathrm{a}$ & $22.4 \mathrm{a}$ & $3.90 \mathrm{~b}$ & $2.22 b c$ \\
\hline & 500 & $44.8 \mathrm{ab}$ & $56.7 c$ & $9.0 \mathrm{a}$ & $36.2 \mathrm{a}$ & $22.9 \mathrm{a}$ & $3.59 \mathrm{c}$ & $2.66 \mathrm{a}$ \\
\hline \multirow{6}{*}{$\begin{array}{c}\text { Red } \\
\text { Perilla }\end{array}$} & 1,000 & $40.3 \mathrm{~b}$ & $60.3 \mathrm{~b}$ & $8.5 \mathrm{a}$ & $34.5 \mathrm{a}$ & $20.4 \mathrm{a}$ & $3.51 \mathrm{c}$ & $2.07 \mathrm{c}$ \\
\hline & 0 & $23.2 \mathrm{~b}$ & $48.3 \mathrm{~b}$ & $8.7 \mathrm{a}$ & $24.1 \mathrm{~b}$ & $13.6 \mathrm{~b}$ & $2.96 \mathrm{~b}$ & $1.89 \mathrm{~b}$ \\
\hline & 125 & $25.1 \mathrm{a}$ & $50.3 \mathrm{~b}$ & $7.6 \mathrm{a}$ & $24.8 \mathrm{~b}$ & $13.3 \mathrm{~b}$ & $3.05 \mathrm{ab}$ & $2.10 \mathrm{a}$ \\
\hline & 250 & $23.9 \mathrm{ab}$ & $59.8 \mathrm{ab}$ & $8.8 \mathrm{a}$ & $27.3 \mathrm{ab}$ & $14.8 \mathrm{ab}$ & $3.39 \mathrm{ab}$ & $2.14 \mathrm{a}$ \\
\hline & 500 & $24.5 \mathrm{a}$ & $67.0 \mathrm{a}$ & $9.3 \mathrm{a}$ & $28.9 \mathrm{a}$ & $16.2 \mathrm{a}$ & $3.89 \mathrm{a}$ & $2.13 \mathrm{a}$ \\
\hline & 1,000 & $21.6 \mathrm{~b}$ & $52.2 \mathrm{~b}$ & $9.2 \mathrm{a}$ & $25.9 \mathrm{ab}$ & $14.2 \mathrm{ab}$ & $3.09 \mathrm{ab}$ & $2.04 \mathrm{a}$ \\
\hline
\end{tabular}

Means in the same column within treatments of each cultivar followed by different letters are significantly different at $p \leq 0.05$ by least significant difference (LSD). Each treatment is assumed to be dependent on the other

Table 5. Effects of salicylic acid (SA) concentration on SPAD, NDVI, and Fv/Fm values of leaves in green and red Perilla frutescens plants over a 7-week period

\begin{tabular}{|c|c|c|c|c|}
\hline \multirow{2}{*}{ Variety } & $\begin{array}{c}\text { SA treatment } \\
(\mu \mathrm{M})\end{array}$ & $\begin{array}{c}\text { SPAD } \\
\text { value }\end{array}$ & $\begin{array}{c}\text { NDVI } \\
\text { value }\end{array}$ & $\begin{array}{c}\text { Fv/Fm } \\
\text { value }\end{array}$ \\
\hline \multirow{3}{*}{$\begin{array}{c}\text { Green } \\
\text { Perilla }\end{array}$} & 0 & $35.0 \mathrm{a}$ & $0.642 \mathrm{c}$ & $0.817 \mathrm{ab}$ \\
\cline { 2 - 5 } & 125 & $34.3 \mathrm{a}$ & $0.683 \mathrm{a}$ & $0.828 \mathrm{a}$ \\
\cline { 2 - 5 } & 250 & $34.6 \mathrm{a}$ & $0.667 \mathrm{~b}$ & $0.824 \mathrm{a}$ \\
\hline \multirow{3}{*}{\begin{tabular}{c} 
Red \\
\cline { 2 - 5 }
\end{tabular}} & 500 & $34.4 \mathrm{a}$ & $0.659 \mathrm{bc}$ & $0.816 \mathrm{ab}$ \\
\cline { 2 - 5 } & 1,000 & $35.5 \mathrm{a}$ & $0.649 \mathrm{c}$ & $0.822 \mathrm{a}$ \\
\hline & 0 & $34.1 \mathrm{a}$ & $0.634 \mathrm{~b}$ & $0.802 \mathrm{c}$ \\
\hline & 250 & $33.5 \mathrm{a}$ & $0.678 \mathrm{a}$ & $0.808 \mathrm{c}$ \\
\hline & 500 & $35.4 \mathrm{a}$ & $0.676 \mathrm{a}$ & $0.813 \mathrm{~b}$ \\
\hline
\end{tabular}

Means in the same column within treatments of each cultivar followed by different letters are significantly different at $p \leq 0.05$ by least significant difference (LSD). Each treatment is assumed to be dependent on the other

Table 6 reveals that the DPPH radical scavenging activity and levels of TP, RA, and CA in green and red Perilla varieties responded differently to SA treatments. The DPPH radical scavenging activity of green $P$. frutescens slowly decreased as SA concentration increased, and significant increases of DPPH radical 
scavenging activity were observed in the 125 and $250 \mu \mathrm{M}$ SA treatments (89.2\% and $91.8 \%$, respectively) compared to controls and the $1,000 \mu \mathrm{M}$ SA treatment (85.2\%). However, significant increases in DPPH radical scavenging activity were noted in red $P$. frutescens with 250 and $500 \mu \mathrm{M}$ SA treatments $(82.8 \%$ and $83.2 \%$, respectively) compared to other treatments $(78.55 \% \sim 80.5 \%)$. The TP levels of green $P$. frutescens under 125 , 250 , and $500 \mu \mathrm{M}$ SA treatments $(160.5 \sim 165.6 \mathrm{mg} \mathrm{GAE} / \mathrm{g} \mathrm{DW})$ were significantly higher than those under control 1,000 $\mu \mathrm{M}$ SA treatment (149.8 and $142.1 \mathrm{mg}$ GAE/g DW, respectively). Nevertheless, the TP concentration of red-leaf plants did not display significant differences in all SA treatments $(123.8 \sim 130.4 \mathrm{mg}$ GAE/g DW). The RA concentration (1593.3 $1773.8 \mathrm{mg} / \mathrm{kg}$ DW) in green Perilla was unaffected by SA treatment, but the RA concentration of red Perilla under the $1000 \mu \mathrm{M}$ SA treatment $(627.0 \mathrm{mg} / \mathrm{kg} \mathrm{DW})$ was significantly lower than under other treatments $(800.5 \sim 886.8 \mathrm{mg} / \mathrm{kg} \mathrm{DW})$. The pattern and trend of CA concentration in both varieties appeared to be similar to SA treatments, and significantly lower CA concentration was seen in the $1000 \mu \mathrm{M}$ SA treatment compared to other treatments. When genotypes were compared across SA treatments, green Perilla plants exhibited higher TP and RA concentration than red Perilla plants with all SA treatments, whereas red Perilla plants exhibited higher CA concentrations than green Perilla plants with all SA treatments.

Table 6. Effects of salicylic acid (SA) concentration on DPPH radical scavenging activity, total phenolic, rosmarinic acid, and caffeic acid concentration of leaves in green and red Perilla frutescens plants over a 7 week period

\begin{tabular}{|c|c|c|c|c|c|}
\hline Variety & $\begin{array}{c}\text { SA } \\
\text { treatment } \\
(\mu \mathrm{M})\end{array}$ & $\begin{array}{c}\text { DPPH } \\
\text { radical scavenging } \\
\text { activity }(\%)\end{array}$ & $\begin{array}{c}\text { Total } \\
\text { phenolic } \\
(\mathrm{mg} \mathrm{GAE} / \mathrm{g} \mathrm{DW})\end{array}$ & $\begin{array}{c}\text { Rosmarinic } \\
\text { acid } \\
(\mathrm{mg} / \mathrm{kg} \mathrm{DW})\end{array}$ & $\begin{array}{c}\text { Caffeic } \\
\text { acid } \\
(\mathrm{mg} / \mathrm{kg} \mathrm{DW})\end{array}$ \\
\hline \multirow{5}{*}{$\begin{array}{l}\text { Green } \\
\text { Perilla }\end{array}$} & 0 & $85.2 \mathrm{c}$ & $149.8 \mathrm{~b}$ & $1524.1 \mathrm{a}$ & $17.5 \mathrm{a}$ \\
\hline & 125 & $91.8 \mathrm{a}$ & $160.5 \mathrm{a}$ & $1623.5 \mathrm{a}$ & $19.2 \mathrm{a}$ \\
\hline & 250 & $89.2 \mathrm{ab}$ & $165.6 \mathrm{a}$ & $1773.8 \mathrm{a}$ & $19.6 \mathrm{a}$ \\
\hline & 500 & $87.8 \mathrm{bc}$ & $160.9 \mathrm{a}$ & $1746.9 \mathrm{a}$ & $19.1 \mathrm{a}$ \\
\hline & 1,000 & $85.2 \mathrm{c}$ & $142.1 \mathrm{~b}$ & $1593.3 \mathrm{a}$ & $14.4 \mathrm{~b}$ \\
\hline \multirow{5}{*}{$\begin{array}{c}\text { Red } \\
\text { Perilla }\end{array}$} & 0 & $78.5 \mathrm{c}$ & $128.9 \mathrm{a}$ & $800.5 \mathrm{a}$ & $48.5 \mathrm{ab}$ \\
\hline & 125 & $80.4 \mathrm{~b}$ & $130.4 \mathrm{a}$ & $860.0 \mathrm{a}$ & $52.7 \mathrm{a}$ \\
\hline & 250 & $82.8 \mathrm{a}$ & $123.8 \mathrm{a}$ & $846.5 \mathrm{a}$ & $41.0 \mathrm{~b}$ \\
\hline & 500 & $83.2 \mathrm{a}$ & $132.7 \mathrm{a}$ & $886.8 \mathrm{a}$ & $40.2 \mathrm{~b}$ \\
\hline & 1,000 & $80.5 \mathrm{~b}$ & $127.1 \mathrm{a}$ & $672.0 \mathrm{~b}$ & $38.6 \mathrm{c}$ \\
\hline
\end{tabular}

Means in the same column within treatments of each cultivar followed by different letters are significantly different at $p \leq 0.05$ by least significant difference (LSD). Each treatment is assumed to be dependent on the other

\section{Discussion}

The fertilizer and SA treatments applied in this study influenced plant growth and biomass production but were not lethal. All measured traits in green Perilla plants were higher than in red Perilla under the same fertilizers (Figure S1), indicating variety differences. This is supported by previous research that showed green Perilla cultivars generally grow faster than red ones in open fields (Martinetti et al., 2012). The application of chemical fertilizers resulted in an increase in nutrient availability and ultimately increased plant yield and quality. In general, higher $\mathrm{N} \%$ fertilizer (30-10-10) treatments in all plants were reflected in higher growth and yield related traits, except for branch number. The latter may be due to the difference in fertilizer treatments between green and red plants, since plant growth and developments largely depends on fertilizer treatments. Optimizing the fertilization strategy is critical for meeting the temporal and spatial $\mathrm{N}$ requirements of crops while protecting the environment and maintaining farm profitability. Other than the fertilizer treatments, most leaves of green and red varieties looked healthy under $125 \mu \mathrm{M} \mathrm{SA}$ treatment compared to other treatments 
(Figure S2), suggesting that the growth of all Perilla plants tended to be more sensitive to $125 \mu \mathrm{M} \mathrm{SA}$ treatment. A high concentration of SA seemed to inhibit plant height and leaf number, since significantly lower values for these parameters were recorded after treatment with 1,000 $\mu \mathrm{M} \mathrm{SA}$. Although our study did not illuminate a specific role for elevated SA in $P$. frutescens, it would appear that $125 \mu \mathrm{M}$ SA may be suitable.

Photosynthesis is sensitive to environmental changes, and under natural conditions photosynthesis is biochemically regulated in response to environmental changes to maintain a balance between the rates of component processes and metabolite concentrations (Habibi, 2018). There is limited information available regarding the eco-physiological development of Perilla plants grown under fertilizer and SA applications. One of the objectives of this study was to employ nondestructive measurements to determine leaf total Chl content and antioxidant activity and develop a precise, integrated, and quantitative measurement of Perilla species under fertilizer and SA applications. In trying to understand the responses to fertilizer and SA levels, photosynthetic parameters and antioxidants induced by long-term periods of fertilizer and SA were identified and characterized, and the effects of fertilizer and SA treatments on the growth, physiological, and antioxidant characteristics of two varieties of $P$. frutescens with different leaf colors were examined in this study. Reflectance spectra can be affected by plant photo-chromes, biochemical components, and tissue configuration (Zou et al., 2011). When different fertilizer applications across species were compared, red Perilla plants exhibited higher SPAD values than green Perilla plants under the same fertilizer treatment, and SPAD values increased as N\% fertilizer increased in all tested plants. It is noteworthy that SPAD values of all species were not affected by SA. Moreover, plant development also differed between the two varieties. Thus, the SPAD of the red Perilla genotype had better responses to fertilizer rations than the green Perilla genotype, indicating that this photosynthetic parameter is suitable for evaluating the growth of specific genotypes treated by specific fertilizer treatment. Notably, higher SPAD and NVDI values were obtained from plants that had more leaves due to being treated with 30-10-10 fertilizer. The SPAD assesses total Chl contents and photosynthetic capacity, and is widely used for the rapid, accurate, and non-destructive measurement of Chl concentrations in leaves (Bonneville and Fyles, 2006). In addition, the NDVI is a sensitive indicator of canopy structure, leaf area index, and Chl content, and it offers a simple, rapid, nondestructive, and precise method to characterize the ecophysiology of plants (Bajwa et al., 2010). This index is correlated with net primary production and photosynthesis rates, and can be used to assess Chl content and as an index of soil fertility (Whitehead et al., 2005). Therefore, NDVI is comprehensively applicable to nondestructively estimate the Chl content of plant leaves and can indicate photosynthetic capacity. In our study, the NDVI values of all plants in relatively higher N\% (i.e., 30-10-10 fertilizer) and $125 \mu \mathrm{M} \mathrm{SA}$ treatments were significant higher compared to lower N\% (i.e., 10-30-20 fertilizer) and the control (zero SA treatment), respectively. Therefore, NVDI can help in the advanced interpretation of the photochemical process in plants. This index was N\% and SA specific and not expressed solely in response to increasing excess of photon energy.

Various ChlF parameters are highly sensitive indicators representing the physiological status of stressed plants, providing a quick means to identify a plant's physiological condition (D'Ambrosio et al., 2006). The $\mathrm{Fv} / \mathrm{Fm}$ reduction indicates that an important portion of the photosynthesis system II (PSII) reaction center was damaged, as the $\mathrm{Fv} / \mathrm{Fm}$ value in healthy leaves is $0.83 \pm 0.04$, which is a typical value for uninhibited plants. This value may be strongly depressed after exposure to a stress, which precipitates the suppression of the electron transfer chain (Wu et al., 2015). A lower value indicates that some proportion of the PSII reaction centers are damaged, which is often observed in plants under conditions of stress (Camejo et al., 2005). In this study, the Fv/Fm value of red Perilla plants displayed significant decreases in 15-10-30 fertilizer (0.764) and $1000 \mu \mathrm{M} \mathrm{SA}(0.798)$ treatments compared to other treatments, suggesting a photoinhibitory effect (Diao et al., 2014). The photo-inhibition of photosynthesis is characterized by a reduction in the quantum yield of photochemistry and reduced ChIF, which entails both the inhibition of PSII and increased thermal deexcitation of excited Chl (Demmig-Adams et al., 1996). However, the reason for the adverse Fv/Fm values for red Perilla leaves in response to 15-10-30 and 1,000 $\mu \mathrm{M} \mathrm{SA}$ is not yet clear. 
A combination of Fv/Fm, SPAD, and NVDI values resulting from fertilizer and SA treatments could be efficient use of land when evaluating plant cultivars in the field. This means that hundreds of individual plants grown under fertilizer and SA treatments can be cost-effectively screened daily, providing ample opportunity to discover individuals that manifest spectral reflectance indicators and exhibit greater antioxidant and metabolite levels among those exhibiting high biomass productions. Our results from evaluating fertilizer and SA treatments in plants used nondestructive spectroscopic measurements that are applicable to large-scale fertilizer management and SA applications for herbaceous plants, thereby enabling fertilizer and SA sources to be more effective. In addition, a better understanding of the growing characteristics of these plants would also aid their effective cultivation for farming in open fields.

Perilla plants are very popular vegetables in Taiwan, and they are also treated as herbaceous plants, functional foods, and nutraceutical products with antioxidant properties. Myriad environmental factors influence plant growth and directly impact biosynthetic pathways, thus affecting the secondary metabolism of bioactive compounds. Optimal fertilizer and SA applications not only increase plant growth but also stabilize the quality of medicinal plants. It is essential to determine the corresponding fertilizer and $S A$ treatments which can maximize Perilla plant biomass production and antioxidant activity when applying a particular N-P-K regimen and SA concentration. Wide variations exist in the antioxidant activity and concentration of the two P. frutescens varieties, with the TP and RA concentration in leaves of green PLE being higher than in red PLE; however, red PLE contained more CA than green PLE under the same fertilizer (except for 20-20-20 fertilizer treatment) or SA conditions, which highlights varietal differences in secondary metabolite synthesis as it relates to fertilizer and SA conditions. These results demonstrated that different varieties responded differently to TP, RA, and CA concentration. Perilla plants are very sensitive to DPPH free radical production in SA treatment, and different cultivars in our DPPH measurements showed a significant difference, but fertilizer treatments did not influence DPPH radical scavenging activity in all plants. More importantly, $P$. frutescens as a common spicy culinary herb seems to deserve a greater health benefit role in our diet due to its nutraceutical values. In addition, the utilization of PLE offers a possibility as a natural food additive, a preservative of foods, and a functional food (Zhao et al., 2019).

Ghaneet al. (2019) revealed that increasing levels of chemical fertilizer reduced the Perilla plant's efficiency in inhibiting free radicals. The total phenolic concentration and antioxidant capacity of Crepidiastrum denticulatum significantly increased with increases in nutrient solution concentration from 0.5 to $2.5 \mathrm{dS} \mathrm{m}^{-1}$ (Park et al., 2016). A higher proportion of potassium at 7 and $14 \mathrm{mmol} \mathrm{L}^{-1}$ increased total phenolic concentration of red and green peppers (Capsicum annuum) compared with lower potassium concentrations of 0.2 and $2 \mathrm{mmol} \mathrm{L}^{-1}$ in nutrient solution (Marín et al., 2009). The application of different nutrient solutions and phytohormones acted positively for accumulating different secondary metabolites in Agastache rugosa Kuntze (Kim et al., 2013). The concentrations of total phenol in red-leaf lettuce plants increased with low nutrient solution temperature (Sakamoto and Suzuki, 2015). Lin et al. (2012) showed increased nitrogen levels caused the production of antioxidant enzymes like APX, SOD, CAT, and POD in Populus yunnanensis plants. Moreover, the application of biological fertilizer increases polyphenol oxidase activity in triticale (KheirizadehArough et al., 2016). Our study suggests that the source of various concentrations of SA had significant influence on the level of antioxidant activity in pot-grown Perilla. N-P-K and SA levels influenced the growth, morphology, and photosynthetic potential of Perilla plants, and different responses by metabolic compounds in leaves depended on the variety of Perilla. These results can be used to optimize the growth and development of plants in fertilizer- and SA-controlled settings. Different fertilizer N-P-K levels had strong effects on the TP, RA, and CA of all plants, and the highest TP and RA levels were obtained when all plants were grown under 10-30-20 fertilizer treatment compared to other treatments. This means that the production of TP and RA was induced in Perilla plants and a low level of CA was maintained by treatment under the 10-30-20 fertilizer. To obtain high production both in plant growth and the accumulation of antioxidants, fertilizer treatments can be applied at different N-P-K levels. For example, compared to control (20-20-20 fertilizer), when applying 15-10-30 and 10-30-20 fertilizer to green and red Perilla plants, respectively, TP and RA levels were remarkably 
and respectively increased without influencing plant growth. Hikosaka et al. (2017) reported that greenhouse cultivation is an effective method for the steady production of medicinal plants because environmental conditions can be controlled for suitable plant growth and quality, so there is also the possibility that bioactive compound concentrations in medicinal plants can be increased under environmental control in greenhouses. The results obtained in this research provide substantive evidence and may serve as an important reference for fertilizer applications in Perilla plants for plant growth and medicinal ingredient content. Optimal cultivation conditions are important for the commercial production of medicinal plants and vegetables, because the cost in fertilizers is a large part of total production costs.

DPPH radical scavenging activity and TP, RA, and CA concentration in Perilla plants were mainly regulated by SA concentration, whereas RA concentration in green plants and TP concentration in red plants were not regulated by SA level. Optimum SA treatment levels for growing green and red Perilla may be better around 125 and $500 \mu \mathrm{M}$ at the pot level, respectively. Changes in DPPH radical scavenging activity and antioxidant activity might be related to the degree of increased chlorosis or senescence of plants during growth periods as they were in plants subjected to $1,000 \mu \mathrm{M}$ of SA and 15-10-30 fertilizer treatments during our study. Antioxidants had already been affected once etiolation or deterioration was evident from leaf appearance. TP concentration accumulation was associated with antioxidant activity, and antioxidant activity against DPPH radicals was correlated with higher metabolite content (Zhou et al., 2014; Lee et al., 2017). Different SA and fertilizer treatments might generate different metabolites, and increased antioxidant activity during growth and development can be considered a mechanism for overcoming chlorosis or senescence. Moreover, environmental conditions during plant growth may affect certain biosynthetic pathways that lead to variability in individual secondary metabolites, and many of them may play key roles in plant adaptation to unfavorable environments. It is very important to maintain a balance between biomass yield and metabolic compound concentration to maximize economic benefits ( $\mathrm{Lu}$ et al., 2018). SA is an effective stress-signaling molecule and elicitor, and its ability to increase the accumulation of secondary metabolites in cultured plant cells and tissues has been extensively studied (Sivanandhan et al., 2012). In addition, SA is also known for its role adapting in plants to changing environments, and influence various stress responses and regulate the physiological and biochemical mechanisms in plants that have adapted to adverse environmental conditions (Boatwright and Karolina, 2013; Janda and Ruellan, 2015; Shen et al., 2016; Lin et al., 2019). The application of SA also enhances the photosynthetic rate and maintains the stability of cell membranes by regulating enzymatic activity (Ghanta et al., 2014). Fertilizer and SA treatments seemed to enable better adaptation to adverse environmental conditions, and induced unfavorable environment adaptation may be directly linked to the coordinated response of TP, RA, and CA and are directly implicated in regulating oxidative metabolism. Therefore, quantifying the optimal fertilizer or SA level from a single environmental factor is crucial for the actual production of medicinal plants in a controlled environment. In our study, SA acted as primary signaling molecule for regulating plant growth and yield-related traits. Metabolite levels may be attributed to scavenging activity on DPPH radicals in the PLE, and the highest scavenging effects in green and red Perilla were observed under 125 and $500 \mu \mathrm{M}$ SA treatment, respectively. The increases in DPPH radical scavenging activity and TP concentration of green PLE were clear with 125 and $250 \mu \mathrm{M}$ SA treatments compared to 1,000 $\mu \mathrm{M}$ SA treatment and control $(0 \mu \mathrm{M} \mathrm{SA})$. However, the increases in RA and CA concentration of red PLE were clear with 250 and $500 \mu \mathrm{M}$ SA treatments compared to $1,000 \mu \mathrm{M}$ SA treatment. Thus, Perilla plants subjected to 125 $\mu \mathrm{M}$ SA can be used as a health food due to high antioxidant activity. However, considering the conditions of its natural habitat, the biosynthesis and accumulation of TP, RA, and CA by Perilla leaves in response to SA and fertilizer treatments is not yet completely clear, thus further studies are needed to confirm the specific signal regulation and transduction components that are present in SA- and fertilizer-mediated improvements in the antioxidants of Perilla plants.

Methanolic extracts were analyzed by C18-HPLC to investigate the effect of fertilizer and SA on each phenolic compound in both Perilla cultivars. Since methanol is an appropriate solvent for the maximum extraction of phenolic compounds (Naczk and Shahidi, 2004), we used it to extract phenolic acids from leaves. 
RA and CA have been reported to have many bioactive properties, such as antioxidant, antimicrobial, and antiinflammatory activity (Swamy et al., 2018; Colica et al., 2018), and were found to be major phenolic compounds in Perilla plants (Osakabe et al., 2002; Dhyani et al., 2019). Skowyra et al. (2014) indicated that the concentration of TP in Perilla leaves was $22.67 \mathrm{mg} \mathrm{GAE} / \mathrm{g} \mathrm{DW}$ using $50 \%$ ethanol for extraction, Hong et al. (2011) found a value of $12.15 \mathrm{mg} \mathrm{GAE} / \mathrm{g}$ DW by extraction with $70 \%$ ethanol, and Chen et al. (2019) reported the Perilla leaves possessed TP concentration of $50 \mathrm{mg}$ GAE/g DW by extraction with acetone. Zhao et al. (2019) reported RA and CA levels in ethanolic extracts of $P$. frutescensleaves of 2.95 and $4.80 \mathrm{mg} / \mathrm{g} \mathrm{DW}$, respectively. The solvent used and the extraction method may affect TP concentration. Our results show that TP, RA, and/or CA concentration in all tested plants were much higher than in the above-mentioned data, suggesting that both species can withstand greater fertilizer and SA impacts on their accumulation, result in greater uniformity of food quality, and can be considered radical scavengers for food and nutraceutical uses. The results obtained in this research could be an important reference for Perilla producers when selecting varieties and applying strategies of fertilizer and SA to achieve their goals in terms of biomass production and antioxidant accumulation. Different Perilla plants subjected to various fertilizer and SA levels can be used as health foods due to their high antioxidant compound content. In the case of the green-leaf Perilla variety, high levels of TP and RA sharing an initial, common biosynthetic pathway is normally present and can be suggested for further cultivation and bioactivity study. Nevertheless, CA can be used to develop an effective method for the selection of red-leaf Perilla variety to improve adaptability to adverse environments, and a better understanding of the relationships of leaf colors with TP, RA, and CA concentration will stimulate more efficient management of Perilla plants. The levels of these compounds can be manipulated by fertilizer and SA to achieve commercial Perilla plant production utilizing rapid, large-scale, precision management practices. The selection of cultivars along with appropriate fertilizer and SA practices are pre-harvest factors that significantly influence the antioxidant activity of Perilla plants. In addition, both Perilla genotypes also exhibit a wide range of variability for most agronomic traits with desired antioxidant activity, and hence could be utilized directly or included in hybridization program. Subjecting plants to fertilizer (e.g., 30-10-10) and SA (e.g., $250 \mu \mathrm{M}$ ) resulted in morphological appearances that were useful for separating cultivars in accordance with antioxidant activity. Therefore, the specific fertilizer and SA applications can be used for screening Perilla plants grown in the field. Our results can also provide Perilla growers the advantage of controlling fertilizer and SA factors to control plant growth and development, and the levels of TP, RA, and CA can attain the desired results while maintaining strict quality standards established for food and drug industries. This can elevate the mission of plant factories from one of producing plants solely for food to also producing plants as medicine (Kozaiet al., 2015; Yamori, 2016).

\section{Conclusions}

The higher N\% fertilizer (30-10-10) treatments increased leaf dry weights and CA concentration in green and red Perilla plants compared to lower N\% (10-30-20) treatments. SA treatments with 125, 250, and $500 \mu \mathrm{M}$ increased leaf dry weight in green and red Perilla plants compared to control. Moreover, SA treatments with 125, 250, and $500 \mu \mathrm{M}$ also increased TP, RA, and CA concentration of leaves in green Perilla plants compared to control. Therefore, SA has the potential to enhance the functional ingredients of Perilla plants. The optimum growth and accumulation of antioxidants in Perilla plants in response to different fertilizer and SA may extend our understanding of the mechanisms related to the economic biosynthesis of TP, RA and CA in plants. The values of SPAD and NDVI of all plants increased as N\% increased, but the NDVI of green Perilla decreased as SA concentration increased. The feasibility of using spectral reflectance indices of fertilizer and SA applications in Perilla species can promote the precision management and cultivation of these plants to maximize the efficiency of the growth, development, and antioxidant potential of Perilla plants grown in pots for economic benefit. 


\section{Authors' Contributions}

YJJ performed the experiments and collected all data sets. CWW and YSC designed the full experiment. KHL wrote the manuscript and reviewed the final manuscript for journal submission. All authors read and approved the final manuscript.

\section{Acknowledgements}

This work was financially supported by the National Taiwan University from Excellence Research Program-Core Consortiums (NTUCCP-107L891308, 108L891308, 109L891208), and the NTU Research Center for Future Earth from The Featured Areas Research Center Program within the framework of the Higher Education Sprout Project by the Ministry of Education (MOE) in Taiwan, and the Ministry of Science and Technology of the Republic of China (MOST-107-2627-M-002-015, 108-2313-B-002-049).

\section{Conflict of Interests}

The authors declare that there are no conflicts of interest related to this article.

\section{References}

Ballester C, Zarco-Tejada PJ, Nicola E, Alarco JJ, Fereres E, Intrigliolo D, Gonzalez-Dugo V (2018). Evaluating the performance of xanthophyll, chlorophyll, and structure-sensitive spectral indices to detect water stress in five fruit tree species. Precision Agriculture 19:178-193. https://doi.org/10.1007/s11119-017-9512-y

Bajwa S, Mishra A, Norman R (2010). Canopy reflectance response to plant nitrogen accumulation in rice. Precision Agriculture 11:488-506. https://doi.org/10.1007\%2Fs11119-009-9142-0

Beta T, Nam S, Dexter J, Sapirstein H (2017). Phenolic content and antioxidant activity of pearled wheat and rollermilled fractions. LWT-Food Science Technology 78:151-159. https://doi.org/10.1094/CC-82-0390

Boatwright JL, Karolina PM (2013). Salicylic acid: An old hormone up to new tricks. Molecular Plant Pathology 14:623634. https://doi.org/10.1111/mpp.12035

Bonneville M, Fyles J (2006). Assessing variations in SPAD-502 Chlorophyll meter measurements and their relationships with nutrient content of trembling aspen foliage. Communications in Soil Science and Plant Analysis 37:525-539. https://doiorg/10.1080/00103620500449385

Caleja C, Barros L, Antonio A, Oliveira M, Ferreira I (2017). A comparative study between natural and synthetic antioxidants: Evaluation of their performance after incorporation into biscuits. Food Chemistry 216:342-346. https://doi.org/10.1016/j.foodchem.2016.08.075

Camejo D, Rodriguez P, Morales M, Dell'Amico J, Torrecillas A, Alarcon J (2005). High temperature effects on photosynthetic activity of two tomato cultivars with different heat susceptibility. Journal of Plant Physiology 162:281-289. https://doi.org/10.1016/j.jplph.2004.07.014

Chao PY, Lin SY, Lin KH, Liu YF, Hsu JI, Yang CM, Lai JY (2014). Antioxidant activity in extracts of 27 indigenous Taiwanese vegetables. Nutrients 6:2115-2130. https://doi.org/10.3390/nu6052115

Chauhan NK, Singh S, Haider S, Lohani H, Kushwaha B (2013). Compositional variability in volatiles from different plant organs of Perilla frutescens L. cultivated in Uttarakhand (India). Journal of Pharmacy Research 6:361-363. https://doi.org/10.1016/j.jopr.2013.03.004

Chen Y, Wang E, Wei Z, Zheng Y, Yan R, Ma X (2019). Phytochemical analysis, cellular antioxidant, and $\alpha$-glucosidase inhibitory activities of various herb plant organs. Industrial Crops and Products 141:111771. https://doi.org/10.1016/j.indcrop.2019.111771

Colica C, Di Renzo L, Aiello V, De Lorenzo A, Abenavoli L (2018). Rosmarinic acid as potential anti-inflammatory agent. Reviews on Recent Clinical Trials 13:240-242. https://doi.org/10.2174/157488711304180911095818 
D’Ambrosio N, Arena C, De Santo AV (2006). Temperature response of photosynthesis, excitation energy dissipation and alternative electron sinks to carbon assimilation in Beta vulgaris L. Environmental and Experimental Botany 55:248-257. https://doi.org/10.1016/j.envexpbot.2004.11.006

Demmig-Adams B, Adams W, Barker DH, Logan BA, Bowlong DR, Verhoeven AS (1996). Using chlorophyll fluorescence to assess the fraction of absorbed light allocated to thermal dissipation of excess excitation. Physiologia Plantarum 98:253-264. https://doi.org/10.1034/j.1399-3054.1996.980206.x

Devitt DA, Morris RL, Fenstermaker LK (2005). Foliar damage, spectral reflectance, and tissue ion concentrations of trees sprinkle irrigated with waters of similar salinity but different chemical composition. HortScience 40:819826. https://doi.org/10.21273/HORTSCI.40.3.819

Dhyani A, Chopra R, Garg M (2019). A review on nutritional value, functional properties, and pharmacological application of perilla (Perilla frutescens L.). Biomedical and Pharmacology Journal 12:649-660. https://doi.org/10.13128/ahs-23828

Diao M, Ma L, Wang J, Cui J, Fu A, Liu HY (2014). Selenium promotes the growth and photosynthesis of tomato seedlings under salt stress by enhancing chloroplast antioxidant defense system. Journal Plant Growth Regulation 33:671-682. https://doi.org/10.1007/s00344-014-9416-2

Ghane M, Mohammadi M, Pirdashti H (2019). Yield and physiological response of Perilla (Perilla frutescens) under different soil fertility treatments. Advances in Horticultural Science 33:205-214. https://doi.org/10.13128/ahs23828

Ghanta S, Datta R, Bhattacharyya D, Sinha R, Kumar D, Hazra S, Mazumdar AB, Chattopadhyay S (2014). Multistep involvement of glutathione with salicylic acid and ethylene to combat environmental stress. Journal of Plant Physiology 171:940-950. https://doi.org/10.1016/j.jplph.2014.03.002

Ghimire BK, Yoo JH, Yu CY, Kim SH, Chung IM (2019). Profiling volatile and phenolic compound composition and characterization of the morphological and biological activities of Perilla frutescence Britton var. japonica accessions. Acta Physiologiae Plantarum 41:108. https://doi.org/10.1007/s11738-019-2890-1

Ghimire BK, Yoo H, Yu CY, Chung IM (2017). GC-MS analysis of volatile compounds of Perilla frutescens Britton var. Japonica accessions: Morphological and seasonal variability. Asian Pacific Journal of Tropical Medicine 10(7):643651. https://doi.org/10.1016/j.apjtm.2017.07.004

Ha TJ, Lee JH, Lee MH, Lee BW, Kwon HS, Park CH, ... Jang DS (2012). Isolation and identification of phenolic compounds from the seeds of Perilla frutescens (L.) and their inhibitory activities against a-glucosidase and aldose refuctase. Food Chemistry 135:1397-1403. https://doi.org/10.1016/j.foodchem.2012.05.104

Habibi G (2018). Effects of mild and severe drought stress on the biomass, phenolic compounds production and photochemical activity of Aloe vera (L.) Burm.f. Acta Agriculturae Slovenica 2018:463-476. https://doi.org/10.14720/aas.2018.111.2.19

Hikosaka S, Iwamoto N, Goto E, Ching HC (2017). Effects of supplemental lighting on growth and medicinal compounds of Japanese Honysuckle Lonicera japonica Thunb. Environmental Control in Biology 55: 71-76. https://doi.org/10.2525/ecb.55.71

Hong E, Park KH, Kim GH (2011). Phenolic-enriched fractions from Perilla frutescens var. acuta: Determinating rosmarinic acid and antioxidant activity. Journal of Food Biochemistry 35:1637-1645. https://doi.org/10.1111/j.1745-4514.2010.00481.x

Huang C, Zhao S, Wang L, Anjum S, Chen M, Zou C (2013). Alteration in chlorophyll fluorescence, lipid peroxidation and antioxidant enzymes activities in hybrid ramie (Boehmeria nivea L.) under drought stress. Australian Journal of Crop Science 7:594-599. http://www.cropj.com/huang3003_7_5_2013_594_599.pdf

Janda M, Ruellan E (2015). Magical mystery tour: Salicylic acid signalling. Environmental and Experimental Botany 114:117-128. https://doi.org/10.1016/j.envexpbot.2014.07.003

Kagawa N, Iguchi H, Henzan M, Hanaoka M (2019). Drying the leaves of Perilla frutescens increases their content of anticancer nutraceuticals. Food Science and Nutrition 7:1494-1501 https://doi.org/10.1002/fsn3.993

Kheirizadeh-Arough Y, Seyed-Sharif R (2016). Biofertilizers and zinc effects on some physiological parameters of triticale under water-limitation condition. Journal of Plant Interactions 11:167-177. https://doi.org/10.1080/17429145.2016.1262914

Kiazolu JB, Intisar A, Zhang L, Wang Y, Zhang R, Wu Z (2016). Phytochemical screening and chemical variability in volatile oils of aerial parts of Morinda morindoides. Natural Product Research 30:2249-2252. https://doi.org/10.1080/14786419.2016.1154058 
Kim SJ, Bok KJ, Lam VP, Park JS (2017). Response of nutrient solution and photosynthetic photon flux density for growth and accumulation of antioxidant in Agastache rugosa under hydroponic culture systems. Protected Horticulture and Plant Factory 26:249-257. https://doi.org/10.12791/KSBEC.2017.26.4.249

Kim YB, Kim JK, Uddin MR, Xu HH, Park WT, Tuan PA, ... Park SU (2013). Metabolomics analysis and biosynthesis of rosmarinic acid in Agastache rugosa Kuntze treated with methyl jasmonate. PLoS One 8:e64199. https://doi.org/10.1371/journal.pone.0064199

Kozai T, Niu G, Takagaki M (2015). Plant factory: An indoor vertical farming system for efficient quality food production. Amsterdam: Academic Press.

Lee YH, Kim B, Kim S, Kim MS, Kim H, Hwang SR, Lee JH (2017). Characterization of metabolite profiles from the leaves of green perilla (Perilla frutescens) by ultra-high-performance liquid chromatography coupled with electrospray ionization quadrupole time-of-flight mass spectrometry and screening for their antioxidant properties. Journal of Food and Drug Analysis 25:776-788. https://doi.org/10.1016/j.jfda.2016.09.003

Levizou E, Drilias P, Psaras GK, Maneta Y (2005). Nondestructive assessment of leaf chemistry and physiology through spectral reflectance measurements may be misleading when changes in trichome density cooccur. New Phytologist 165:463-472. https://doi.org/10.1111/j.1469-8137.2004.01250.x

Lin T, Zhu X, Zhang F (2012). The interaction effect of cadmium and nitrogen on Populus yunnanensis. Journal of Agricultural Science 4:125-134.

Lin KH, Huang SB, Wu CW, Chang YS (2019). Effects of salicylic acid and calcium chloride on heat tolerance of Poinsettia. HortScience 54:499-504. https://doi.org/10.21273/HORTSCI13566-18

Liu J, Wan Y, Zhao Z, Chen H (2013). Determination of the content of rosmarinic acid by HPLC and analytical comparison of volatile constituents by GC-MS in different parts of Perilla frutescens (L.) Britt. Chemistry Central Journal 7:61. https://doi.org/10.1186/1752-153X-7-61

Lu N, Takagaki M, Yamori W, Kagawa N (2018). Flavonoid productivity optimized for green and red forms of Perilla frutescens via environmental control technologies in plant factory. Journal of Food Quality 2018:4270279. https://doi.org/10.1155/2018/4270279

Lu N, Bernardo EL, Tippayadarapanich C, Takagaki M, Kagawa N, Yamori W (2017). Growth and accumulation of secondary metabolites in perilla as affected by photosynthetic photon flux density and electrical conductivity of the nutrient solution. Frontiers in Plant Science 8:708. https://doi.org/10.3389/fpls.2017.00708

Marin A, Rubio JS, Martinez V, Gil MI (2009). Antioxidant compounds in green and red peppers as affected by irrigation frequency, salinity and nutrient solution composition. Journal of the Science of Food and Agriculture 89:13521359. https://doi.org/10.1002/jsfa.3594

Martinetti L, Ferrante A, Bassoli A, Borgonovo G, Tosca A, Spoleto P (2012). Characterization of some qualitative traits in different perilla cultivars. Acta Horticulturae 939:301-308. https://doi.org/10.17660/ActaHortic.2012.939.39

Naczk M, Shahidi F (2004). Extraction and analysis of phenolic in food. Journal of Chromatography A 1054:95-111.

Ogawa E, Hikosaka S, Goto E (2018). Effects of nutrient solution temperature on the concentration of major bioactive compounds in red perilla. Journal of Agricultural Meteorology 74:71-78. https://doi.org/10.2480/agrmet.D-1700037

Osakabe N, Yasuda A, Natsume M, Sanbongi C, Kato Y, Osawa T, Yoshikawa T (2002). Rosmarinic acid, a major polyphenolic component of Perilla frutescens, reduces lipopolysaccharide (LPS)-induced liver injury in Dgalactosamine (D-GalN)- sensitized mice. Free Radical Biology and Medicine 33:798-806. https://doi.org/10.1016/s0891-5849(02)00970-X

Park SY, Oh SB, Kim SM, Cho YY, Oh MM (2016). Evaluating the effects of a newly developed nutrient solution on growth, antioxidants, and chicoric acid contents in Crepidiastrum denticulatum. Horticulture, Environment, and Biotechnology 57:478-486. https://doi.org/10.1007\%2Fs13580-016-1060-2

Pintha K, Tantipaiboonwong P, Yodkeeree S, Chaiwangyen W, Chumphukam O, Khantamat O, ... Suttajit M (2018). Thai perilla (Perilla frutescens) leaf extract inhibits human breast cancer invasion and migration. Maejo International Journal of Science and Technology 12:112-123.

Saeb K, Gholamrezaee S (2012). Variation of essential oil composition of Melissa officinalis L. leaves during different stages of plant growth. Asian Pacific Journal of Tropical Biomedicine 2:547-549.

Sakamoto M, Suzuki T (2015). Effect of root-zone temperature on growth and quality of hydroponically grown red leaf lettuce (Lactuca sativa L. cv. Red Wave). American Journal of Plant Sciences 6:2350-2360. https://doi.org/10.4236/ajps.2015.614238 
Selmar D, Kleinwächter M (2013). Stress enhances the synthesis of secondary plant products: the impact of the stressrelated over-reduction on the accumulation of natural products. Plant and Cell Physiology 54:817-826. https://doi.org/10.1093/pcp/pct054

Skowyra M, Falguera V, Azman NA, Segovia F, Almajano MP (2014). The effect of Perilla frutescens extract on the oxidative stability of model food emulsions. Antioxidants3:38-54. https://doi.org/10.3390/antiox3010038

Shen H, B Zhao, J Xu, X Zheng, W Huang (2016). Effects of salicylic acid and calcium chloride on heat tolerance in Rhododendron 'Fen Zhen Zhu'. Journal of the American Society for Horticultural Science 141:363-372. https://doi.org/10.21273/JASHS.141.4.363

Sivanandhan G, Arun M, Mayavan S, Rajesh M, Mariashibu TS, Manickavasagam M, ... Ganapathi A (2012). Chitosan enhances withanolides production in adventitious root cultures of Withania somnifera (L.). Dunal. Industry Crops and Products 37:124-129. https://doi.org/10.1016/j.indcrop.2011.11.022

Swamy MK, Sinniah UR, Ghasemzadeh A (2018). Anticancer potential of rosmarinic acid and its improved production through biotechnological interventions and functional genomics. Applied Microbiology Biotechnology 102:77757793. https://doi.org/10.1007/s00253-018-9223-y

Taga MS, Miller EE, Pratt DE (1984). Chia seeds as a source of natural lipid antioxidants. Journal American Oil Chemistry Society 61:928-931. https://doi.org/10.1007/BF02542169

Umakanta S, Oba S (2018). Response of nutrients, minerals, antioxidant leaf pigments, vitamins, polyphenol, flavonoid and antioxidant activity in selected vegetable amaranth under four soil water content. Food Chemistry 252:72-83. https://doi.org/10.1016/j.foodchem.2018.01.097

Weng JH, Jhaung LH, Lin RJ, Chen HY (2010). Relationship between photochemical efficiency of photosystem II and the photochemical reflectance index of mango tree: Merging data from different illuminations, seasons, and leaf colors. Tree Physiology 30:469-478. https://doi.org/10.1093/treephys/tpq007

Whitehead D, Boelman NT, Turnbull MH, Griffin KL, Tissue DY, Barbour MM, ... Peltzer DA (2005). Photosynthesis and reflectance indices for rainforest species in ecosystems undergoing progression and retrogression along a soil fertility chronosequence in New Zealand. Oecologia 144:233-244.

Wu CW, Lin KH, Lee MC, Peng YL, Chou TY, Chang YS (2015). Using chlorophyll fluorescence and vegetation indices to predict the timing of nitrogen demand in Pentas lanceolata. Korean Journal Horticulture Science Technology 33:845-853.

Yamori W (2016). Photosynthetic response to fluctuating environments and photoprotective strategies under abiotic stress. Journal Plant Research 129:379-395. https://doi.org/10.1007/s10265-016-0816-1

Yoshiki Y, Kahhara T, Sakabe S, Yamasaki T (2001). Superoxide and DPPH radical-scavenging activities of soyasponin beta bg related to gallic acid. Bioscience Biotechnology Biochemistry 65:2162-2165. https://doi.org/10.1271/bbb.65.2162

Yoshimatsu K (2012). Innovative cultivation: Hydroponics of medicinal plants in the closed-type cultivation facilities. Journal of Traditional Medicines 29:30-34. https://doi.org/10.11339/jtm.29.30

Zhao Y, Kong H, Zhang X, Hu X, Wang M (2019). The effect of Perilla (Perilla frutescens) leaf extracts on the quality of surimi fish balls. Food Science and Nutrition 7:2083-2090. https://doi.org/10.1002/fsn3.1049

Zhou X, Yan L, Yin P, Shi L, Zhang L, Liu L, Ma C (2014). Structural characterisation and antioxidant activity evaluation of phenolic compounds from cold-pressed Perilla frutescens var. arguta seed flour. Food Chemistry 164:150-157. https://doi.org/10.1016/j.foodchem.2014.05.062

Zou J (2011). Proteomics of rice in response to heat stress and advances in genetic engineering for heat tolerance in rice. Plant Cell Report 30:2155-2165. https://doi.org/10.1007/s00299-011-1122-y 
OPEN ACCESS The journal offers free, immediate, and unrestricted access to peer-reviewed research and scholarly work. Users are allowed to read, download, copy, distribute, print, search, or link to the full texts of the articles, or use them for any other lawful purpose, without asking prior permission from the publisher or the author.

(c) (

License - Articles published in Notulae Botanicae Horti Agrobotanici Cluj-Napoca are Open-Access, distributed under the terms and conditions of the Creative Commons Attribution (CC BY 4.0) License. (C) Articles by the authors; UASVM, Cluj-Napoca, Romania. The journal allows the author(s) to hold the copyright/to retain publishing rights without restriction. 